\title{
Enhancement of Lytic Activity of HEWL Adsorbed on Biochar by the Optimization of Adsorption Conditions
}

\author{
Hidetaka Noritomi ${ }^{1}$, Shunichi Kurihara ${ }^{1}$, Nobuyuki Endo ${ }^{2}$, Satoru Kato ${ }^{1}$, Katsumi Uchiyama ${ }^{1}$ \\ ${ }^{1}$ Department of Applied Chemistry for Environment, Tokyo Metropolitan University, Tokyo, Japan \\ ${ }^{2}$ EEN Co., Ltd., Tokyo, Japan \\ Correspondence: Hidetaka Noritomi, Department of Applied Chemistry for Environment, Tokyo Metropolitan \\ University, Tokyo, 192-0397, Japan. Tel:81-42-677-2824. E-mail: noritomi@tmu.ac.jp
}

Received: Oct. 18, 2020 Accepted: Oct. 23, 2020 Online Published: Oct. 28, 2020

doi:10.5539/ijc.v12n2p45 URL: https://doi.org/10.5539/ijc.v12n2p45

\begin{abstract}
We have found that HEWL (hen egg white lysozyme) is effectively immobilized on biochar through adsorption, and the amount of HEWL adsorbed on biochar is strongly dependent on the $\mathrm{pH}$ value of adsorption solutions. The structure of HEWL adsorbed on biochar changed by the $\mathrm{pH}$ value of adsorption solutions and became similar to that of native HEWL at acidic pH value, although the structure of HEWL solubilized in the solution was the same in the range between $\mathrm{pH} 4$ and 9. On the other hand, the lytic activity of biochar-adsorbed HEWL toward Micrococcus lysodeikticus was markedly influenced by the $\mathrm{pH}$ value of adsorption solutions and increased with decreasing the $\mathrm{pH}$ value. Moreover, the addition of $\mathrm{KCl}$ to adsorption solutions enhanced the lytic activity of biochar-adsorbed HEWL.
\end{abstract}

Keywords: adsorption, biochar, hen egg white lysozyme, lytic activity

\section{Introduction}

The industrial dependence on fossil fuels has caused an enormous amount of carbon dioxide to be emitted into the air, and as the result, the climate change has anthropogenically been driven (Olivier et al., 2017). Accordingly, as an alternative of fossil fuels, the utilization of biomass materials, which are carbon neutral, for energies and functional materials has become crucial to reduce greenhouse gas emissions (Ho \& Show, 2015). However, most of biomass materials such as forestry residues have hardly been utilized in the field of functional materials. Accordingly, the development in the high value-added application of biomass materials has been desired to provide the multiple effective utilization system of biomass materials.

Bioprocess consists of environmental benign systems, and has been widely applied to the synthesis, the sensor, the fuel cell, and so on (Heinzle et al., 2006). Bioprocess has generally included enzymes, which are biocatalysts that exhibit the outstanding biological activity and specificity under mild conditions (Sheldon \& Woodley, 2018; Silwana et al., 2014). To enhance the stability and recycling of enzymes, enzyme immobilization has been carried out mainly by attaching enzymes to solid carriers (Zdata et al., 2018; Noritomi et al., 2020). The performances of immobilized enzymes such as activity, specificity, and stability are markedly dependent on the kind of carriers, the method of immobilizing enzymes on carriers, and the experimental condition of enzyme immobilization. Therefore, the immobilization of enzymes on carriers can bring out the desired performance of enzymes.

To apply biomass materials to carriers for enzyme immobilization, we have prepared biochar from biomass materials such as forestry residues by pyrolysis at low temperatures under a nitrogen atmosphere. As a result, we have found that enzymes are effectively immobilized on biochar through adsorption (Noritomi,2019). Moreover, we have reported that biochar-adsorbed enzymes exhibit the excellent tolerance not only in hot water but also in organic solvents (Noritomi, 2019; Noritomi et al., 2019), although physical and chemical stresses such as heat and organic solvents generally cause enzymes to be denatured and inactivated.

In the present work, we have addressed the question of how the experimental condition of enzyme immobilization affect the activity of biochar-adsorbed enzymes when biochar is used as an enzyme carrier, and adsorption is employed as the method of enzyme immobilization. As a model enzyme, hen egg white lysozyme (HEWL) has been employed. Since HEWL catalyzes the hydrolysis of the $\beta-1,4$ glycosidic linkage between the $N$-acetylmuramic acid and $\mathrm{N}$-acetylglucosamine components of peptidoglycan in the cell membrane of bacteria, the cell bursting or lysis in natural hypotonic solutions is enhanced by using HEWL (Illanes, 1999). Consequently, HEWL has been used as antibacterial 
agents and enzyme-sterilizing filters (Tanaka et al., 2003). Moreover, HEWL has well been investigated regarding its structure, properties, and functions (Jollès, 1996).

\section{Method}

\subsection{Materials}

Lysozyme from hen egg white (HEWL) (EC 3.2.1.17, 46400 units/mg solid, MW=14300, pI=11) and Micrococcus lysodeikticus (ATCC No. 4698) were purchased from Sigma-Aldrich Co. (St. Louis, USA).

\subsection{Preparation of Bamboo Charcoal Powder}

To derive biochar from bamboo wastes, under a nitrogen atmosphere, bamboo wastes were dried at $180{ }^{\circ} \mathrm{C}$ for $2 \mathrm{hr}$, were pyrolyzed at $450{ }^{\circ} \mathrm{C}$ for $2 \mathrm{hr}$, were carbonized at $350{ }^{\circ} \mathrm{C}$ for $3 \mathrm{hr}$, and then were cooled at $100{ }^{\circ} \mathrm{C}$ for $1 \mathrm{hr}$ by pyrolyzer (EE21 Pyrolyzer, EEN Co. Ltd., Japan). Bamboo charcoal powder (BCP) having the mean diameter of $7 \mu \mathrm{m}$ was prepared by grinding the resultant bamboo charcoal with jet mill (100AS, Fuji Sangyo Co. Ltd., Japan).

\subsection{Characterization of Bamboo Charcoal Powder}

The SEM micrograph was obtained using a scanning electron microscope (JSM-7500FA, JEOL, Japan) operating at 15 $\mathrm{kV}$. The sample for SEM was prepared on a carbon tape without vapor deposition.

The $\zeta$ potential for BCP was measured by electrophoretic light scattering (ELS-Z2, OTSUKA Electronics Co. Ltd.).

The sample was outgassed at $300^{\circ} \mathrm{C}$ for $8 \mathrm{~h}$ prior to the nitrogen adsorption measurements. The specific surface area of BCP was calculated with the use of the Brunauer-Emmett-Teller (BET) method using a micropore system (BELSORP-mini II, BEL JAPAN, INC.).

The surface of BCP was analyzed by X-ray photoelectron spectroscopy (XPS) (Quantum-2000, ULVAC-PHI Co. Ltd.) operating at an X-ray beam size of $100 \mu \mathrm{m}$.

\subsection{Adsorption of HEWL onto Bamboo Charcoal Powder}

As a typical procedure, the buffer solution containing $500 \mu \mathrm{M}$ hen egg white lysozyme (HEWL) and $3 \mathrm{~g} / \mathrm{L} \mathrm{BCP}$ was incubated at $25{ }^{\circ} \mathrm{C}$ and $120 \mathrm{rpm}$ for $24 \mathrm{hr}$ (Noritomi et al., 2011). After adsorption, the mixture was filtrated with a membrane filter (pore size: $0.1 \mu \mathrm{m}$, Millipore Co. Ltd., USA). The amount of HEWL adsorbed on BCP was calculated by subtracting the amount of HEWL included in the supernatant liquid after adsorption from the amount of HEWL in its aqueous solution before adsorption. The amount of HEWL was measured at $280 \mathrm{~nm}$ by UV/vis spectrophotometer (UV-1800, Shimadzu Co. Ltd., Japan).

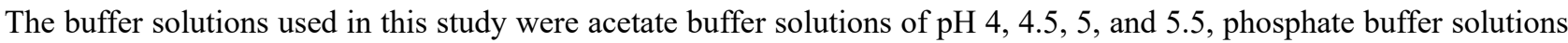

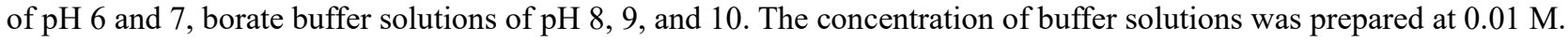

\subsection{Measurement of Activity of HEWL Adsorbed on Bamboo Charcoal Powder}

The lytic activity of HEWL was determined using Micrococcus lysodeikticus as a substrate (Noritomi et al., 2011). Three hundred and fifty $\mu \mathrm{L}$ of $0.01 \mathrm{M}$ phosphate buffer solution ( $\mathrm{pH}$ 7.0) containing BCP-adsorbed HEWL was added to $21 \mathrm{~mL}$ of $0.01 \mathrm{M}$ phosphate buffer solution (pH 7.0) containing $200 \mathrm{mg} / \mathrm{L}$ Micrococcus lysodeikticus, and the mixture was incubated by stirring at $25^{\circ} \mathrm{C}$. The absorbance of the mixture was periodically measured at $450 \mathrm{~nm}$ by UV/vis spectrophotometer (UV-1800, Shimadzu Co. Ltd.).

Bacterial lysis can be correlated by a first order kinetics. The lysis rate constant $(\mathrm{k})$ is calculated by

$$
\ln \left(\mathrm{A}^{\mathrm{o}}{ }_{450} / \mathrm{A}_{450}\right)=k \mathrm{t}
$$

where $t, A^{\circ} 450$, and $A_{450}$ are the reaction time, the absorbance of the substrate solution at $450 \mathrm{~nm}$ at $\mathrm{T}=0$, and the absorbance of the substrate solution at $450 \mathrm{~nm}$ at $\mathrm{T}=\mathrm{t}$, respectively. The relative activity (R. A.) is defined as

$$
\text { R. A. }=100 \times k / k_{o}
$$

where $k_{o}$ is the maximum lysis rate constant of BCP-adsorbed HEWL when the $\mathrm{pH}$ value of adsorption solutions is changed and is lysis rate constant of BCP-adsorbed HEWL in the adsorption solution without $\mathrm{KCl}$ when $\mathrm{KCl}$ concentration of adsorption solutions is changed.

\subsection{Characterization of HEWL}

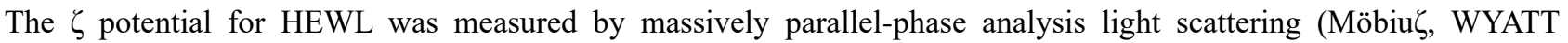
Technology Co. Ltd.).

CD measurements of HEWL were carried out using a Jasco spectropolarimeter model J-820. The CD spectra were run on the HEWL solutions of $0.1 \mathrm{mg} / \mathrm{mL}$ in a quartz cell with $1.0 \mathrm{~cm}$ path length at an appropriate temperature. 
FTIR measurements of native and BCP-adsorbed HEWL were carried out using a Jasco FT/IR spectrometer model FT/IR-4100. A KBr pellet containing $0.5 \mathrm{mg}$ of native or BCP-adsorbed HEWL powder per $100 \mathrm{mg}$ of $\mathrm{KBr}$ was prepared, and the measurements were performed using 512 scans under $4.0 \mathrm{~cm}^{-1}$ resolution.

\section{Results and Discussion}

\subsection{Characterization of Bamboo Charcoal Powder}

Biochar is the carbon opulent product prepared by heating biomass in a closed container with little or no available air through the process of pyrolysis (Abrol \& Sharma, 2019; Franciscus et al., 2010). Biochar has already been used as a soil amendment and has recently incremented attention due to an alternative for organic waste management and a method sustainable storage of carbon for abbreviating greenhouse gas emissions. On the other hand, bamboo has been felled to prevent landslides in the bamboo forest due to heavy rain and deforestation due to bamboo, and a large amount of bamboo waste has been produced (Dura \& Hiura, 2006; Yamamoto et al., 1995). In the present work, biochar has been prepared by pyrolyzing bamboo waste at low temperatures under a nitrogen atmosphere to explore the utilization of bamboo wastes.

Figure 1 shows the scanning electron micrograph of BCP. The surface state of BCP relatively looked like smooth under the magnification measured in the present work. The specific surface area and pore volume of BCP were $317 \mathrm{~m}^{2} / \mathrm{g}$ and $0.13 \mathrm{~m}^{3} / \mathrm{g}$, respectively. Furthermore, the pore diameter peak of BCP was less than $0.8 \mathrm{~nm}$. These results indicate that there are micropores on the surface of BCP.

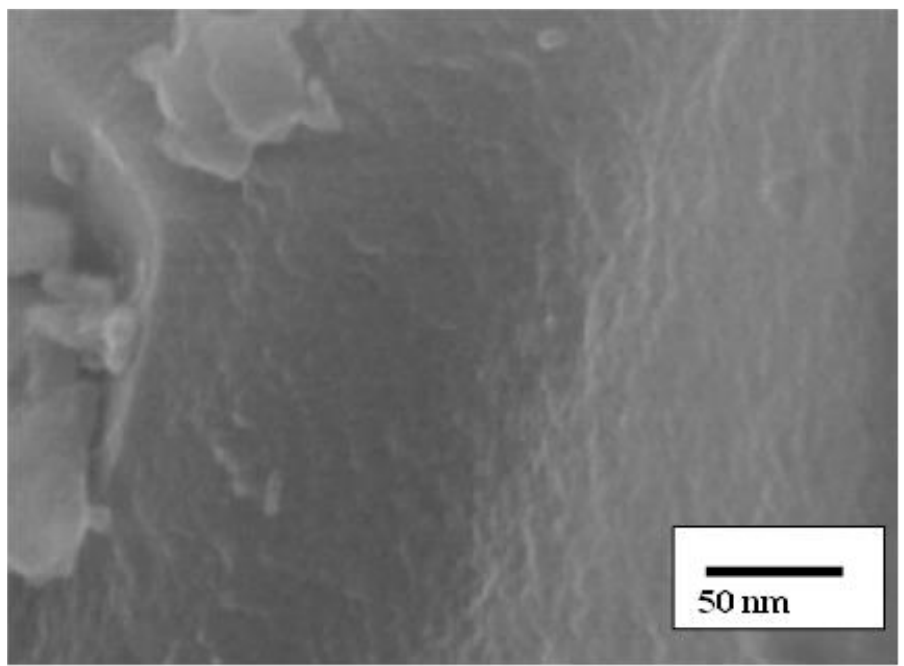

Figure 1. SEM image of bamboo charcoal powder (BCP)

Figure 2 shows XPS spectrum of BCP. Besides carbon which was main element, $16 \%$ of oxygen was detected. Additionally, waveform separation of $\mathrm{C} 1$ peaks of narrow scan spectrum mainly showed single $\mathrm{C}-\mathrm{O}$ bond, which was assigned to the alcohol, ether, phenol, and enol-keto groups. Moreover, the carbonyl, carboxyl, and phenolic groups were detected by DD/MAS ${ }^{13} \mathrm{C}-\mathrm{NMR}$ spectroscopy (Noritomi et al., 2019). These results indicate that BCP has a charged surface.

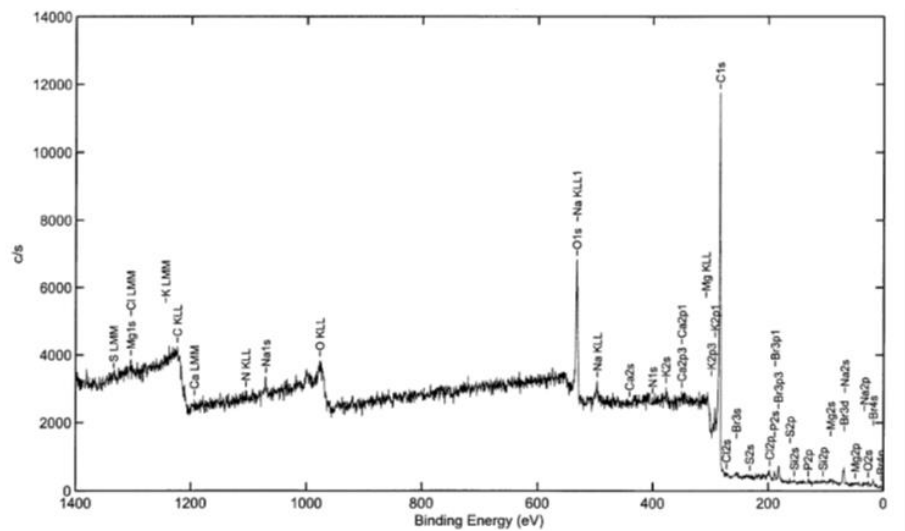

Figure 2. XPS spectrum of BCP 
Figure 3 shows the relation between the $\zeta$-potential of HEWL and BCP and the solution $\mathrm{pH}$. The $\zeta$ potential of BCP in aqueous solutions was strongly dependent on the solution $\mathrm{pH}$, similar to that of HEWL, since the surface of BCP had the functional groups as mentioned above.

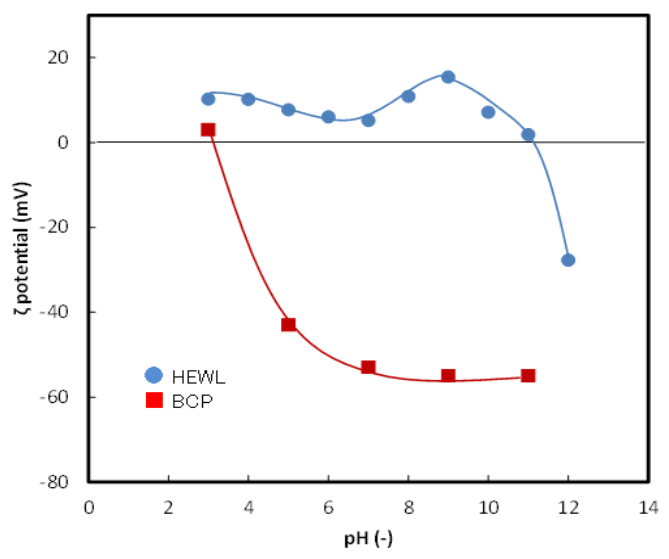

Figure 3. Relation between the $\zeta$-potential of HEWL and BCP and the solution $\mathrm{pH}$

\subsection{Adsorption of HEWL on Bamboo Charcoal Powder}

Figure 4 shows the relation between the amount of HEWL adsorbed on $\mathrm{BCP}$ and the $\mathrm{pH}$ value of adsorption solutions. The amount of HEWL adsorbed on $\mathrm{BCP}$ increased from the acidic to neutral $\mathrm{pH}$, reached the maximum value around neutral $\mathrm{pH}$, and gradually decreased in the alkaline region. As shown in Fig. 3, the $\zeta$ potential of BCP dropped from acidic $\mathrm{pH} 4$ to neutral $\mathrm{pH}$ and was almost constant in the alkaline region, while that of HEWL showed the positive value below pH 11 which is the isoelectric point (pI) of HEWL (Jollès, 1996). The amount of HEWL adsorbed on BCP tended to increase with more negative value of $\zeta$ potential of BCP. Accordingly, the result indicates that the stronger electrostatic interaction between the positively charged HEWL and the negatively charged surface of BCP exhibits the larger amount of HEWL adsorbed on BCP.

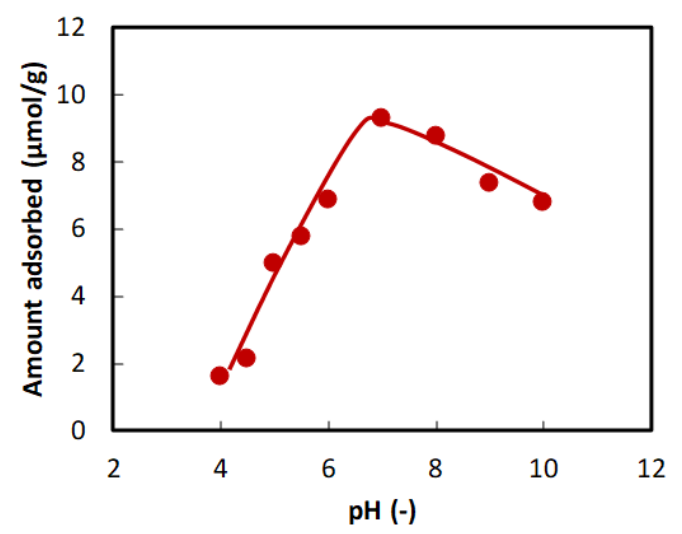

Figure 4. Relation between the amount of HEWL adsorbed on BCP and the $\mathrm{pH}$ of adsorption solutions

Figure 5 shows the relation between the amount of HEWL adsorbed on $\mathrm{BCP}$ and the $\mathrm{KCl}$ concentration of adsorption solutions at $\mathrm{pH}$ 7. The amount of HEWL adsorbed on $\mathrm{BCP}$ decreased with increasing $\mathrm{KCl}$ concentration. The addition of $\mathrm{KCl}$ to adsorption solutions did not influence the transparency of solutions, and any precipitate did not occur. The addition of inorganic salts such as $\mathrm{KCl}$ causes the electrostatic interaction between positively charged $\mathrm{HEWL}$ and negatively charged $\mathrm{BCP}$ to be shielded due to the electrostatic screening effect. Thus, the result indicates that the decrease in the amount of HEWL adsorbed on BCP results from the decrease in the electrostatic interaction between HEWL and $\mathrm{BCP}$ due to the addition of $\mathrm{KCl}$ to adsorption solutions. 


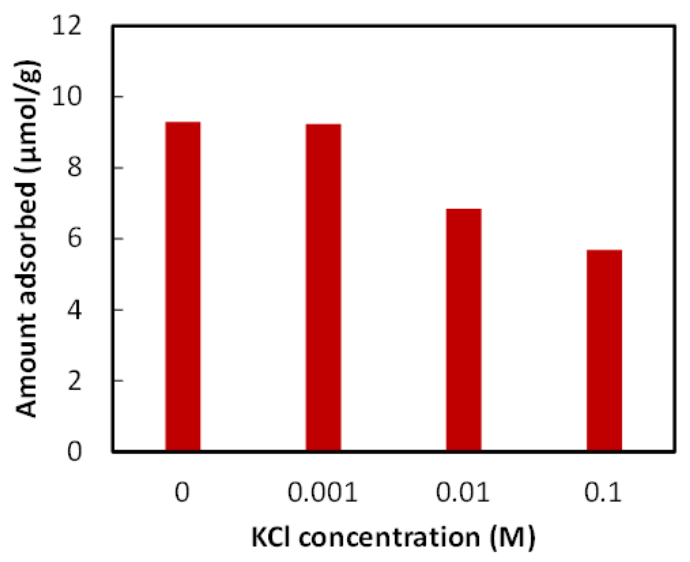

Figure 5. Relation between the amount of HEWL adsorbed on $\mathrm{BCP}$ and the $\mathrm{KCl}$ concentration of adsorption solutions at $\mathrm{pH} 7$

\subsection{Structure of HEWL Adsorbed on Bamboo Charcoal Powder}

To investigate the change of the structure of HEWL before and after adsorption, we have measured the CD spectra of HEWL dissolved in aqueous solutions before adsorption and the FTIR spectra of HEWL adsorbed on BCP after adsorption. Figure 6 shows the CD spectra of HEWL dissolved in aqueous solutions at different pH. In the far-UV region $(200-250 \mathrm{~nm})$, the CD spectrum of HEWL was independent on the solution $\mathrm{pH}$. The CD spectra in the far-UV correspond to the secondary structure of enzymes (Fasman, 1996; Chen et al., 1972). Similarly, the mean residue ellipticities at 215 and $222 \mathrm{~nm}$ are assigned to $\beta$-sheet and $\alpha$-helix, respectively. Likewise, the CD spectrum of HEWL in the near-UV region $(250-350 \mathrm{~nm})$ did not almost change with the solution $\mathrm{pH}$. The CD spectra in the near-UV correspond to the local asymmetric environment of aromatic amino acid residues based on the tertiary structure of enzymes (Fasman, 1996; Ikeda \& Hamaguchi, 1969). The mean residue ellipticities at 283 and $294 \mathrm{~nm}$ are assigned to tryptophan residues, and the mean residue ellipticity at $289 \mathrm{~nm}$ is assigned to tyrosine residues. Accordingly, the result of CD spectra indicates that the structure of HEWL is not influenced by the solution $\mathrm{pH}$.
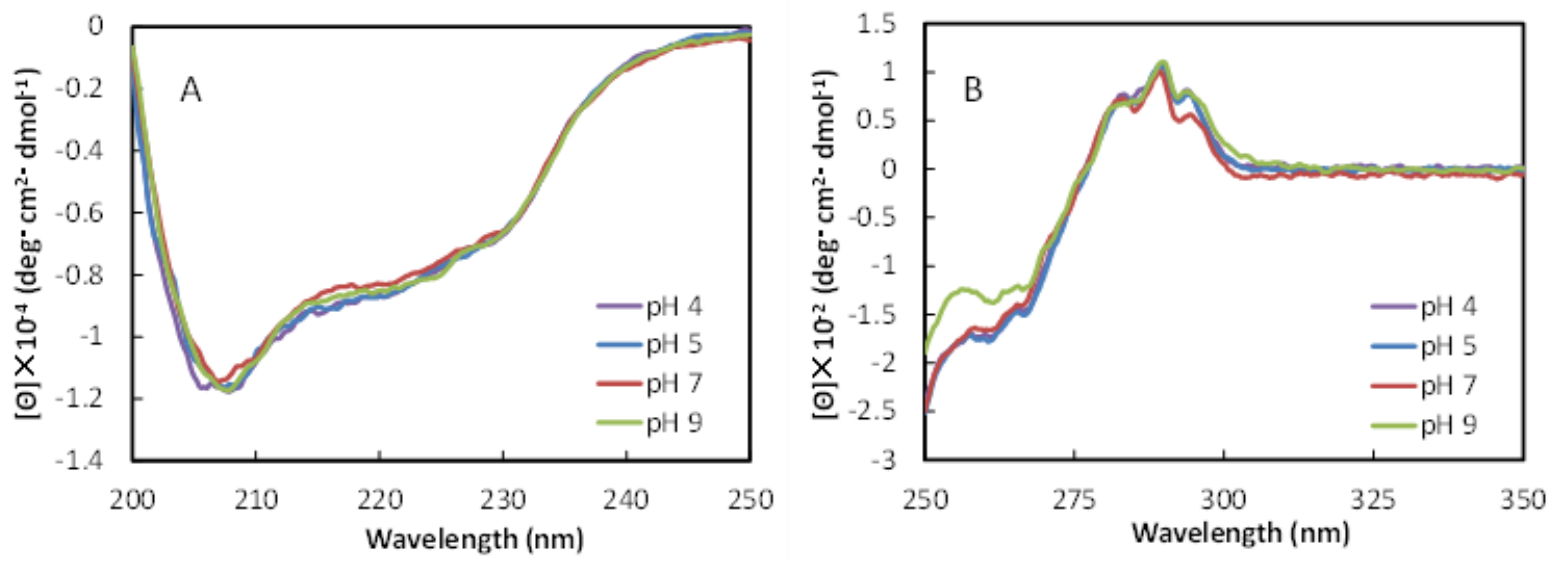

Figure 6. (A) CD spectra of HEWL dissolved in buffer solutions at different $\mathrm{pH}$ in far-UV region. (B) CD spectra of HEWL dissolved in buffer solutions at different $\mathrm{pH}$ in near-UV region

Figure 7 shows the FTIR spectra of native HEWL and HEWL adsorbed onto BCP at the different $\mathrm{pH}$ value of adsorption solutions. The most sensitive spectral region to protein secondary structural components is amide I (1700 $1600 \mathrm{~cm}^{-1}$ ), which is due almost entirely to the $\mathrm{C}=\mathrm{O}$ stretch vibrations of the peptide linkages (Surewicz \& Mantsch, 1988). The spectral pattern of BCP-adsorbed HEWL was influenced by the $\mathrm{pH}$ value of adsorption solutions. The spectral pattern of BCP-adsorbed HEWL exhibited a specific shape of secondary structures, similar to native HEWL. Accordingly, the secondary structure of HEWL was kept to some extent after adsorption. In order to evaluate the change 
in the secondary structure of BCP-adsorbed HEWL, we have assessed the ratio of the absorbance at $1681 \mathrm{~cm}^{-1}$ to the absorbance at $1647 \mathrm{~cm}^{-1}\left(\mathrm{ABS}_{1681} / \mathrm{ABS}_{1647}\right)$, since the bands located at ca. $1681 \mathrm{~cm}^{-1}$ and $1647 \mathrm{~cm}^{-1}$ are assigned to intramolecular $\beta$-sheet and $\alpha$-helix, respectively (Surewicz \& Mantsch, 1988). Table 1 shows the absorbance ratio of $1681 \mathrm{~cm}^{-1}$ to $1647 \mathrm{~cm}^{-1}$ of IR spectra of HEWL adsorbed onto BCP at different $\mathrm{pH}$ of adsorption solutions. The $\mathrm{ABS}_{1681} / \mathrm{ABS}_{1647}$ ratio altered by the $\mathrm{pH}$ value of adsorption solutions and increased with a decrease in the $\mathrm{pH}$ value of adsorption solutions. Especially, the $\mathrm{ABS}_{1681} / \mathrm{ABS}_{1647}$ ratios at solution $\mathrm{pH} 4$ and 5 were similar to that of native HEWL. On the other hand, the $\mathrm{ABS}_{1681} / \mathrm{ABS}_{1647}$ ratios at solution $\mathrm{pH} 7$ and 9 were different to some extent from that of native HEWL. As seen in Fig. 3, since BCP was more negatively charged in the range from neutral to alkaline $\mathrm{pH}$ compared to the range of acidic $\mathrm{pH}$, the electrostatic interaction between $\mathrm{HEWL}$ and $\mathrm{BCP}$ at solution $\mathrm{pH} 7$ and 9 was higher than that at solution $\mathrm{pH} 4$ and 5. Consequently, these results indicate that the structure of HEWL changes by the adsorption of HWEL on BCP, and stronger electrostatic interaction between HEWL and BCP induces larger structural change of HEWL, which results in lower $\mathrm{ABS}_{1681} / \mathrm{ABS}_{1647}$ ratio.

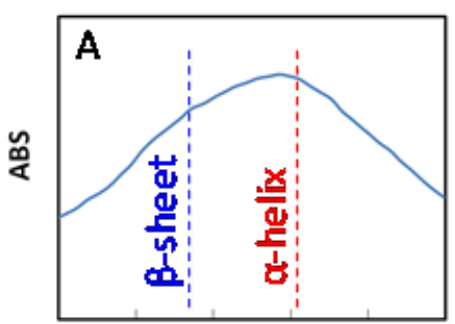

172517001675165016251600 Wave number $\left(\mathrm{cm}^{-1}\right)$

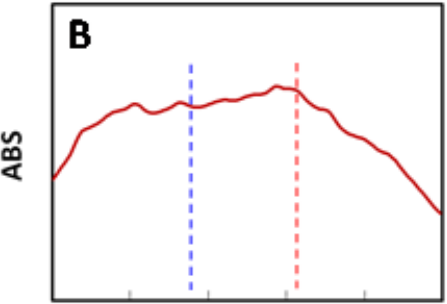

172517001675165016251600 Wave number $\left(\mathrm{cm}^{-1}\right)$

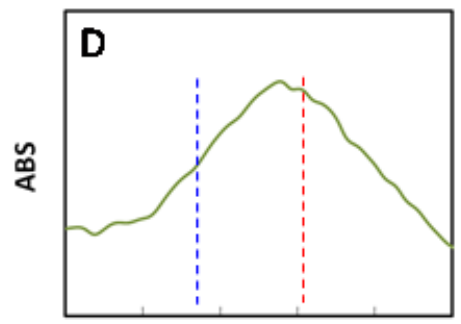

172517001675165016251600

Wave number $\left(\mathrm{cm}^{-1}\right)$

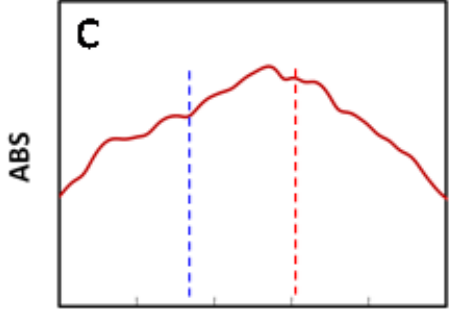

172517001675165016251600 Wave number $\left(\mathrm{cm}^{-1}\right)$

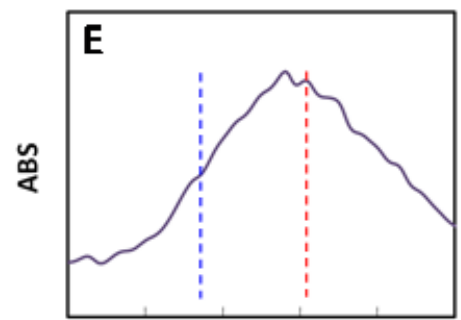

172517001675165016251600 Wave number $\left(\mathrm{cm}^{-1}\right)$

Figure 7. (A) FTIR spectrum of native HEWL. (B) FTIR spectrum of HEWL adsorbed onto BCP at pH 4. (C) FTIR spectrum of HEWL adsorbed onto BCP at pH 5. (D) FTIR spectrum of HEWL adsorbed onto BCP at pH 7. (E) FTIR spectrum of HEWL adsorbed onto BCP at $\mathrm{pH} 9$

Table 1. Absorbance ratios of $1681 \mathrm{~cm}^{-1}$ to $1647 \mathrm{~cm}^{-1}$ of IR spectra of HEWL adsorbed onto BCP at different $\mathrm{pH}$ of adsorption solutions

\begin{tabular}{llll}
\hline & Samples & $\mathrm{pH}$ of adsorption solutions $(-)$ & $\mathrm{ABS}_{1681} / \mathrm{ABS}_{1647}(-)$ \\
\hline A & Native HEWL & - & 0.88 \\
B & BCP-adsorbed HEWL & 4 & 0.92 \\
C & BCP-adsorbed HEWL & 5 & 0.86 \\
D & BCP-adsorbed HEWL & 7 & 0.69 \\
E & BCP-adsorbed HEWL & 9 & 0.61 \\
\hline
\end{tabular}

\subsection{Activity of BCP-Adsorbed HEWL}

Figure 8 shows the relation between the relative activity of BCP-adsorbed HEWL and the $\mathrm{pH}$ value of adsorption solutions. The relative activity of BCP-adsorbed HEWL was strongly dependent on the $\mathrm{pH}$ value of adsorption solutions, and dramatically increased with decreasing the $\mathrm{pH}$ value of adsorption solutions. As shown in Table 1, BCP-adsorbed 
HEWL kept its native structure at the acidic $\mathrm{pH}$ value of adsorption solutions. Accordingly, the result indicates that the high activity of HEWL adsorbed on BCP is obtained by the maintenance in the native structure of HEWL after adsorption.

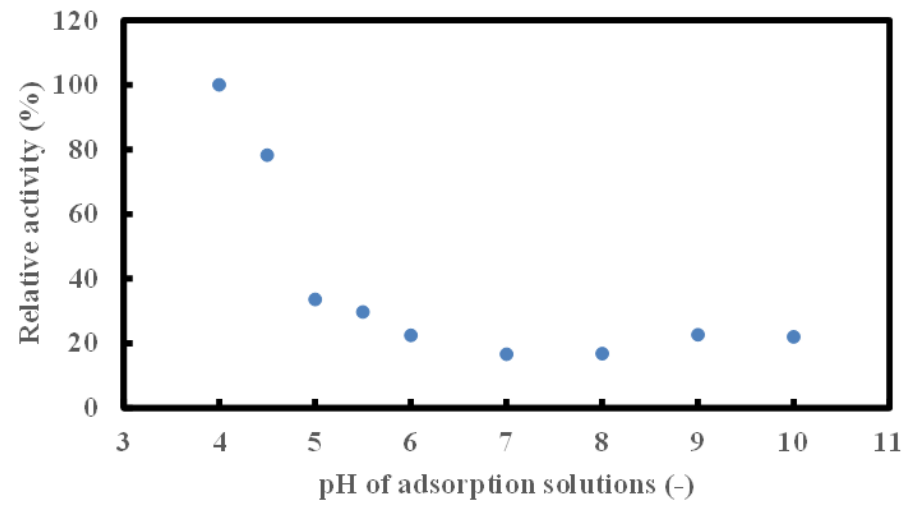

Figure 8. Relation between the relative activity of BCP-adsorbed HEWL and the $\mathrm{pH}$ of adsorption solutions

To estimate the influence of ionic strength of adsorption solutions on the activity of BCP-adsorbed HEWL, we have carried out the adsorption of HEWL onto $\mathrm{BCP}$ at $\mathrm{pH} 7$ and different $\mathrm{KCl}$ concentrations. Figure 9 shows the relationship between the relative activity of $\mathrm{BCP}$-adsorbed $\mathrm{HEWL}$ and the $\mathrm{KCl}$ concentration of adsorption solutions at $\mathrm{pH}$ 7. The relative activity of $\mathrm{BCP}$-adsorbed HEWL prepared in adsorption solutions with $\mathrm{KCl}$ was superior to that without $\mathrm{KCl}$ and increased with increasing the $\mathrm{KCl}$ concentration. As mentioned above, the electrostatic interaction between HEWL and $\mathrm{BCP}$ decreases in an increase in $\mathrm{KCl}$ concentration. From the result, it indicates that the high activity of HEWL adsorbed on BCP is obtained by using adsorption solutions at the acidic $\mathrm{pH}$ or by adding $\mathrm{KCl}$ to adsorption solutions to weaken the electrostatic interaction between HEWL and BCP.

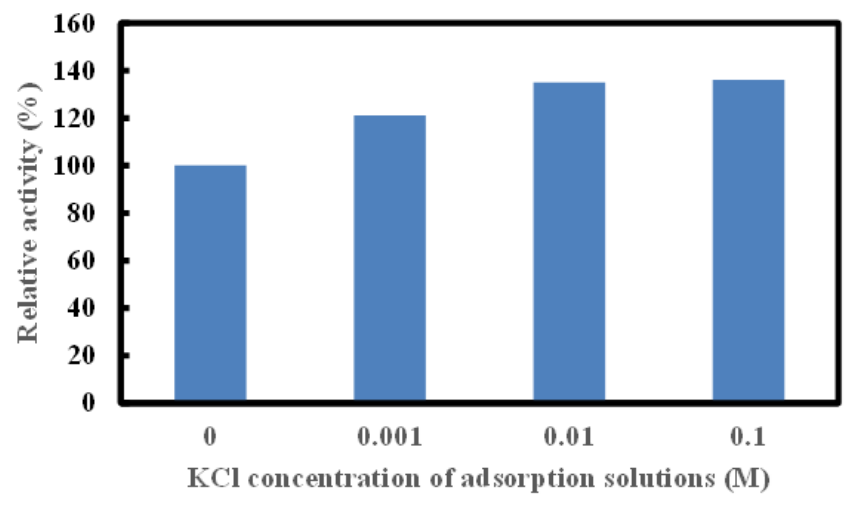

Figure 9. Relation between the relative activity of BCP-adsorbed HEWL and the $\mathrm{KCl}$ concentration of adsorption solutions at $\mathrm{pH} 7$

\section{Conclusions}

We have demonstrated that the lytic activity of BCP-adsorbed HEWL can be controlled by selecting adsorption conditions, similar to the amount of HEWL adsorbed on BCP. The $\zeta$ potential of BCP and HEWL in aqueous solutions was strongly dependent on the solution $\mathrm{pH}$. Accordingly, the electrostatic interaction between HEWL and BCP was influenced by the solution $\mathrm{pH}$. The maximum amount of HEWL adsorbed on BCP was observed around $\mathrm{pH} 7 \mathrm{where}$ the electrostatic interaction between HEWL and BCP was strong. On the other hand, the structure of HEWL adsorbed on BCP altered with an increase in the electrostatic interaction between HEWL and BCP. Furthermore, the high activity of HEWL adsorbed on BCP was obtained by using adsorption solutions at the acidic $\mathrm{pH}$ or by adding $\mathrm{KCl}$ to adsorption 
solutions to weaken the electrostatic interaction between HEWL and BCP. Consequently, it would be expected that the recovery of enzymes in bioseparations and the enzyme activity in bioreactors and biosensors are enhanced by using $\mathrm{BCP}$ as adsorbents and enzyme carriers.

\section{References}

Abrol, V., \& Sharma, P. (2019). Biochar-An Imperative Amendment for Soil and the Environment (1 ${ }^{\text {st }}$ ed.). InTech. https://doi.org/10.5772/intechopen.74890

Chen, Y. H., Yang, J. T., \& Martinez, H. M. (1972). Determination of the secondary structures of proteins by circular dichroism and optical rotatory dispersion. Biochemistry, 11, 4120-4131. https://doi.org/10.1021/bi00772a015

Dura, D. B., \& Hiura, H. (2006). Expansion characteristics of bamboo stand and sediment disaster in south western Japan. Pakistan Journal of Biological Sciences, 9, 622-631. https://doi.org/10.3923/pjbs.2006.622.631

Fasman, G. D. (1996). Circular Dichroism and the Conformational Analysis of Biomolecules (1st ed.). Plenum Press. https://doi.org/10.1007/978-1-4757-2508-7

Franciscus, V., Lee, J. S., Catarina, A., Marijn, V. D. V., \& Iason, D. I. (2010). Biochar Application to Soils - A Critical Scientific Review of Effects on Soil Properties, Processes and Functions. European Commission, Luxembourg.

Heinzle, E., Biwer, A. P., \& Cooney, C. L. (2006). Development of Sustainable Bioprocesses, Modeling and Assessment. John Wiley \& Sons, Ltd. https://doi.org/10.1002/9780470058916

Ho, Y. C., \& Show, K. Y. (2015). A perspective in renewable energy production from biomass pyrolysis-challenges and prospects. Current Organic Chemistry., 19, 423-436. https://doi.org/10.2174/1385272819666150119223318

Ikeda, K., \& Hamaguchi, K. (1969). The binding of $N$-acetylglucosamine to lysozyme: Studies on circular dichroism. $J$. Biochem., 66, 513-520. https://doi.org/10.1093/oxfordjournals.jbchem.a129176

Illanes, A. (1999). Stability of biocatalysts. Electronic Journal of Biotechnology., 2, 1-9. https://doi.org/10.2225/vol2-issue1-fulltext-2

Jollès, P. (1996). Lysozymes: Model Enzymes in Biochemistry and Biology (1st ed.). Birkhäuser Verlag. https://doi.org/10.1007/978-3-0348-9225-4

Noritomi, H. (2019). Application of biochar to enzyme carrier for stress tolerance of enzymes. In Abrol V. \& Sharma P. (Eds.), Biochar-An Imperative Amendment for Soil and the Environment (pp. 75-95). London: InTech. https://doi.org/10.5772/intechopen.82094

Noritomi, H., Kai, R., Endo, N., Kato, S., \& Uchiyama, K. (2019). Thermal stabilization of HEWL by adsorption on biochar, Journal of Materials Science Research, 8, 30-36. https://doi.org/10.5539/jmsr.v8n4p30

Noritomi, H., Kai, R., Iwai, D., Tanaka, H., Kamiya, R., Tanaka, M., Muneki, K., \& Kato, S. (2011). Increase in thermal stability of proteins adsorbed on biomass charcoal powder prepared from plant biomass wastes. Journal of Biomedical Science and Engineering, 4, 692-698. https://doi.org/10.4236/jbise.2011.411086

Noritomi, Y., Kuboki, T., \& Noritomi, H. (2020). Estimation of immobilized horseradish peroxidase in a low salt concentration for an irreversible electrochemical system. Results in Chemistry, 2, 1-7. https://doi.org/10.1016/j.rechem.2020.100055

Olivier, J. G. J., Muntean, M., \& Peters, J. A. H. W. (2017). Trends in Global $\mathrm{CO}_{2}$ Emissions: Report.

Sheldon, R. A., \& Woodley, J. M. (2018). Role of biocatalysis in sustainable chemistry, Chemical Reviews, 118, 801-838. https://doi.org/10.1021/acs.chemrev.7b00203

Silwana, B., Horst, C. V. D., \& Iwuoha, E. (2014). Aerometric determination of cadmium, lead, and mercury metal ions using a novel polymer immobilized horseradish peroxidase biosensor system. Journal of Environmental Science and Health Part A, 49, 1501-1511. https://doi.org/10.1080/10934529.2014.937169

Surewicz, W. K., \& Mantsch, H. H. (1988). New insight into protein secondary structure from resolution-enhanced infrared spectra. Biochimica et Biophysica Acta, 952, 115-130. https://doi.org/10.1016/0167-4838(88)90107-0

Tanaka, A., Isomae, K., \& Gokano, M. (2003). Air cleaning filter. US Patent, 6579352.

Yamamoto, S., Nishimura, N., \& Matsui, K. (1995). Natural disturbance and tree species coexistence in an old-growth beech - dwarf bamboo forest, southwestern Japan. Journal of Vegetation Science, 6, 875-886. https://doi.org/10.2307/3236402

Zdata, J., Meyer, A.S., Jesionowski, T., \& Pinelo, M. (2018). A general overview of support materials for enzyme 
immobilization: characteristics, properties, practical utility. Catalysts, 8, 92-118. https://doi.org/10.3390/catal8020092

\section{Copyrights}

Copyright for this article is retained by the author(s), with first publication rights granted to the journal.

This is an open-access article distributed under the terms and conditions of the Creative Commons Attribution license (http://creativecommons.org/licenses/by/4.0/). 